\title{
RESEARCH
}

\section{Calcitonin induces stem cell-like phenotype in prostate cancer cells}

\author{
Afaf Aldahish, Ajay Kale, Ahmed Aljameeli and Girish V Shah \\ Pharmacology, College of Pharmacy, University of Louisiana at Monroe, Monroe, Louisiana, USA \\ Correspondence should be addressed to G V Shah: shah@ulm.edu
}

\begin{abstract}
Stem cell-like-cancer cells are key drivers of tumor growth, metastasis, and relapse of cancer following remission. Prostate stem cell-like cancer cells isolated from human prostate cancer (PC) biopsies express CD44 ${ }^{+} / \alpha_{2} \beta_{1}{ }^{\text {hi }} / \mathrm{CD} 133^{+}$cell surface markers and can self-renew in vitro. Expression of calcitonin (CT) and its receptor (CTR) is frequently elevated in PCs and activation of CT-CTR axis in non-invasive PC cells induces an invasive phenotype. We investigated whether CT-CTR autocrine axis induces stem cell-like phenotype in two PC cell lines. CT-CTR axis in these cell lines was activated by enforced expression of CTR. The cells were then examined for the changes in the expression of CD44 and CD133, collagen adherence, tumorigenic, metastatic and repopulating characteristics. The activation of CT-CTR axis led to a large increase in adherence to collagen and a remarkable increase of CD44 and CD133 in PC-3 and LNCaP cells. This was accompanied by a strong increase in tumorigenic, metastatic and repopulation properties of PC cells. However, the mutation of CTR-C PDZ-binding site in CTR almost abolished CTR-mediated increases in stem cell-like characteristics of PC cells. These results support an important role for CT-CTR axis in the progression of PC from localized cancer to an aggressive form, and a majority of proinvasive CTR actions may be mediated through its interaction with its partner protein at the PDZ-binding site. These results suggest that CT/CTR can serve as a valuable target to prevent the generation of stem-like PC cells.
\end{abstract}

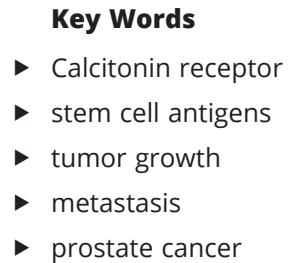

Endocrine-Related Cancer (2019) 26, 815-828

\section{Introduction}

Prostate cancer (PC) is the most frequently diagnosed cancer in men, exceeded only by lung cancer as the leading cause of cancer-related mortality among men (Ferlay et al. 2010). Despite recent advances in the field, effective therapy for patients with locally advanced and/or metastatic disease is not effective (Shibata et al. 2013). Although androgen and its receptors are important for the maintenance and function of the prostate, other factors such as neuroendocrine secretions are known to contribute to the progression of PC to its androgen-independent form (Beltran et al. 2016). Recent evidence suggests the presence of a biologically distinct subpopulation of prostate tumor cells, which possess stem cell-like properties such as the expression of stem cell antigens CD44 and CD133 and are described as cancer stem cells or cancer repopulating cells (CRCs) (Oktem et al. 2014a, b). These cells have proliferative potential to maintain tumor bulk and resist chemotherapy in order to repopulate the tumor and cause metastasis after cancer treatment (Reya et al. 2001). Moreover, these cells also display other phenotypes such as high levels of the $\alpha_{2 \beta 1}$ integrins, a potential to establish and maintain a prostate epithelium with secretory activity, higher invasive and self-renewal properties. Moreover, these cells can be 
enriched by their strong affinity to specific ECMs such as collagen I, collagen IV or laminin.

Calcitonin (CT), a neuroendocrine peptide, and its receptor are frequently elevated in prostate cancer and the activation of CT-CTR autocrine axis in non-invasive PC cells has been shown to induce an invasive phenotype in multiple PC cell lines (Shah et al. 1992, 1994, 2008, Thomas \& Shah 2005, Thomas et al. 2006, 2007b). CT activates multiple cellular events such as disassembly of tight junctions and adherence junctions, activation of Wnt- $\beta$-catenin signaling, cadherin switching, induction of epithelial-to-mesenchymal transition (EMT), and major changes in cell adhesion properties of PC cells to extracellular matrix (ECM) (Thomas et al. 2007a, Shah et al. 2009a). CTR expressed in the prostate gland is type II receptor, which is dually coupled to stimulatory

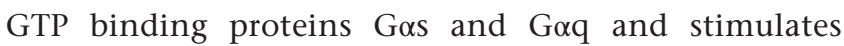
cyclic-AMP- and phospholipase C-activated pathways (Shah et al. 1994, Chien \& Shah 2001). Recent studies from this laboratory have shown that CTR contains a canonical PDZ-binding site in its cytoplasmic tail, and the site plays a critical role in CTR-mediated increase in invasiveness of PC cells and in the formation of distant metastases by orthotopically implanted PC cells in immunodeficient mice (Aljameeli et al. 2016). Our recent studies have shown that CTR-ZO1 interaction is critical for proinvasive and metastatic actions of CT in primary prostate cancers as well as multiple prostate cancer cell lines including LNCaP and PC-3 cells (Aljameeli et al, 2016). Ability of CTR to interact with ZO-1 can be abolished by the removal of PDZ-binding site ESSA on CTR-C-tail by $\triangle E S S$ mutation. PC cell lines expressing mutant CTR (CTR- $\Delta$ ESS) do not display proinvasive characteristics and fail to grow to form tumors and distant metastases when implanted orthotopically in the prostates of nude mice (Aljameeli et al, 2016). Since PC stem-like cells exhibit characteristics similar to those exhibited by PC cells with activated CT-CTR axis, the primary objective of the present study was to examine whether CT-CTR axis induces or increases the stem cell-like characteristics of PC cells and identify the potential mechanism associated with this CTR action. We fractionated PC cells with collagen I because the activation of CT-CTR axis in these cells induces the surface expression of the $\alpha 2$-integrin subunit and rapid adherence to type I collagen (Thomas et al. 2007a, Sariisik et al. 2013). We then examined stem cell-like and oncogenic characteristics of PC-3 and LNCaP cell subfractions. The expression of stem cell antigens CD44, CD133 as well as their oncogenic characteristics such as proliferation, migration, spheroid-forming ability and metastasis-forming abilities were examined.

\section{Materials and methods}

\section{Materials}

Antibodies for flow cytometry CD44, CD133 and

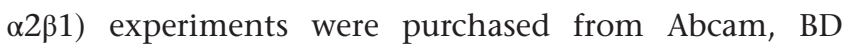
Transduction Laboratories (San Jose, CA, USA), Proteintech (Rosemont, IL, USA) and Bio-Rad respectively. Collagen I was purchased from Sigma-Aldrich. The working collagen solution was prepared by diluting the stock collagen solution 1:5 with tissue culture grade water. Culture dishes were coated with the diluted collagen solution under UV light inside the culture hood for at least $1 \mathrm{~h}$.

\section{Methods}

\section{Animals}

Male balb/c nu/nu mice (6-8 weeks old) were purchased from Envigo and housed one per cage in micro-isolator units in a barrier facility on a high-efficiency particulate air (HEPA)-filtered rack under standard conditions of 12-h light/dark cycles, fed ad lib on a standard autoclaved laboratory diet, and quarantined for 1 week prior to their use in the study.

\section{Surgical orthotopic implantation}

The surgical orthotopic implantation was performed under ketamine/xylazine anesthesia as previously described (Chien et al. 1999, Shah et al. 2008) (Shah et al. 2009b). In brief, fast aderent and slow adherent cell suspensions of three, PC-3v, PC-3CTRwt and PC3-CTRAESS cell lines $\left(1 \times 10^{5}\right.$ cells $\left./ 20 \mu \mathrm{L}\right)$ were injected into the dorsal prostate, the mice were maintained on the laboratory diet ad libitum for up to 60 days, and were regularly monitored for tumor growth/metastasis with fluorography using Kodak 4000 MM imaging station (Eastman Kodak Company, Rochester) and killed within 60 days (Shah et al. 2008). Six animals per group were used in this group of experiments. This number was derived by using the power calculations for $P<0.05$ as previously described (Dell et al. 2002, Charan $\&$ Kantharia 2013). The sample size was determined to test the hypothesis that fast adherent PC3-CTRwt cells will form significantly larger prostate xenografts along with distant metastases as compared to those produced by PC-3v or PC3-CTR $\triangle E S S$ cells. The animals were observed on a daily basis and killed by $\mathrm{CO}_{2}$ inhalation when they met the following humane endpoint criteria: prostration, 
skin lesions, significant body weight loss, difficulty breathing, epistaxis, rotational motion and body temperature drop. Several organs were collected, fixed and examined for tumor metastasis. At necropsy, primary tumor and other organs were harvested and weighed. The tissues were fixed in neutral buffered formalin and processed for H\&E staining. The use of animals was necessary to evaluate tumorigenicity and metastasizing ability of cell lines expressing wild type or mutant CTR. Killing was performed by trained investigators. All animal procedures were conducted strictly under the protocol approved by the Institutional Animal Care and Use Committee at University of Louisiana at Monroe. These procedures are in accordance with the principles and procedures outlined by the NIH.

\section{Cell culture}

PC-3 and LNCaP cells were obtained from ATCC and maintained as recommended by the provider (Shah et al. 2009b). PC-3 cells express CT but lack CTR. We activated CT-CTR axis in PC-3 and LNCaP cells by enforced expression of either CTR-wt or CTR- $\triangle \mathrm{ESS}$, a mutant CTR that lacks the PDZ-binding site as described recently (Aljameeli et al. 2016). PC-3 cells were stably transfected with the carrier plasmid without CTR insert. The cell lines and modified sublines were used only up to passage 12 . Primary cell lines were used within 6 months of their purchase. Therefore, PC-3 and PC-3CTR cell lines were authenticated by STR profiling at the John Hopkins University Medical Center (Thakkar et al. 2016). The sublines were used immediately after the stable transfection.

\section{Western blotting}

The lysate fractions of PC-3 and LNCaP sublines expressing either control plasmid or expressing CTR-wt or CTR- $\triangle$ ESS were boiled for 5 min in 2 Laemmli solution containing $20 \mathrm{mM}$ dithiothreitol, and $50 \mathrm{~g}$ of protein was loaded per lane of 10\% SDS-polyacrylamide gel, and fractionated proteins were electrically transferred to a nitrocellulose membrane. The blots were incubated with appropriate antisera as described under 'Results' for $18 \mathrm{~h}$ at $4^{\circ} \mathrm{C}$, followed by appropriate horseradish peroxidaseconjugated secondary antisera. The immune complexes were visualized on chemiluminescence radiography film using Western blot ECL detection system. The blots were then washed and reprobed for $\beta$-actin. The same experiment was repeated two more times. The density of the bands was semiquantitatively estimated by densitometry.
Fractionation of PC-3 and LNCaP cells on the basis of collagen adherence capacity

PC cells were fractionated into fast adherent, slow adherent and non-adherent cells based on their ability to adhere to collagen within $5 \mathrm{~min}, 20 \mathrm{~min}$ or longer (Fig. 1A). The cells were seeded on collagen I-coated plates for $5 \mathrm{~min}$. The adhered cells were used as fast adherents. The cells that did not adhere to collagen after 5 min were harvested and reseeded on a new collagen-coated plate for $20 \mathrm{~min}$. This fraction of adhered cells was used as slow adherent cells. The cells that did not adhere to collagen after 20 min were considered as non-adherent cells (Fig. 1A). All cell lines used for the fractionation were from passages six or earlier.

\section{Flow cytometry}

After fractionation, the cells were washed twice in PBS, and labeled with CD44, CD133 and $\alpha 2 \beta 1$ antibodies for $45 \mathrm{~min}$ on ice in dark. The cells were then washed and stained with FITC-conjugated secondary antibodies for 45 min and analyzed using FACSCalibur flow cytometer. Data acquisition and analysis were done using CellQuest2 ${ }^{\mathrm{TM}}$ software (BD Biosciences).

\section{Immunocytochemistry}

To check whether both CD44 and CD133 are present on the surface of same cells, we immunolabeled collagenfractionated PC-3, PC3-CTRwt and PC3-CTR $\triangle E S S$ cells with primary antibodies (mouse Anti-CD44, BD Transduction Laboratories; rabbit Anti-CD133, Proteintech) for overnight at $4^{\circ} \mathrm{C}$. The appropriate secondary antibodies conjugated with fluorophores FITC or TRITC were applied. After washes, the slides were observed under Nikon Optiphot-2 microscope equipped for epifluorescence. The images were captured with Retiga 1300 camera connected to an iMac computer loaded with the iVision image analysis program (Biovision Technologies, Exton, PA, USA). All antibodies were characterized for specificity and cross-reactivity as described earlier.

\section{Image analysis and interpretation}

Approximately ten different microscope fields of each ICC chambers were photographed, and the images were quantitatively analyzed using iVision Image Analysis program. The images were then analyzed for co-localization of CD44 and CD133, as well as for quantification of immunostaining.

Co-localization of CD44 and CD133 in labeled cell population was checked using co-localization module of 
A

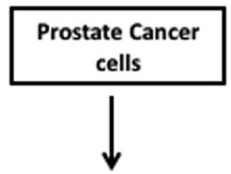

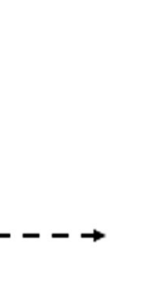
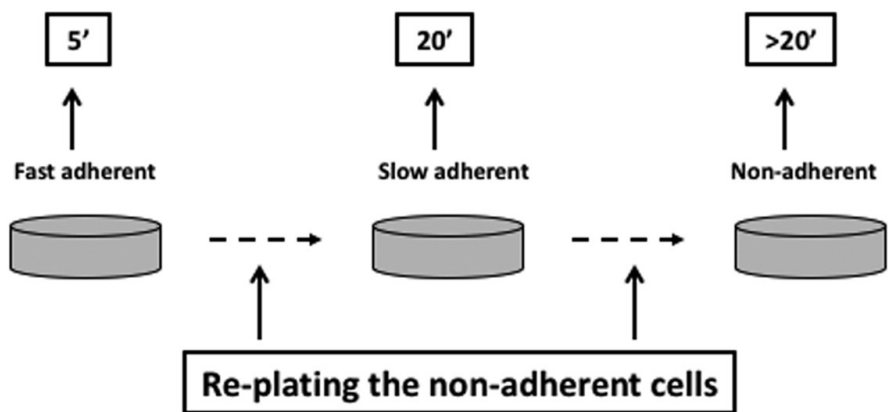

B

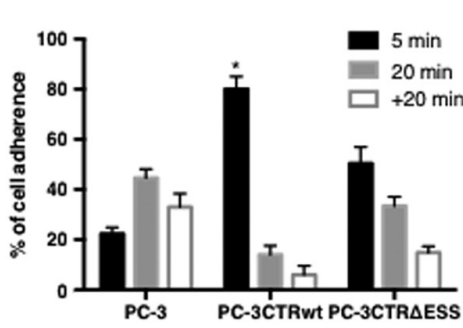

C

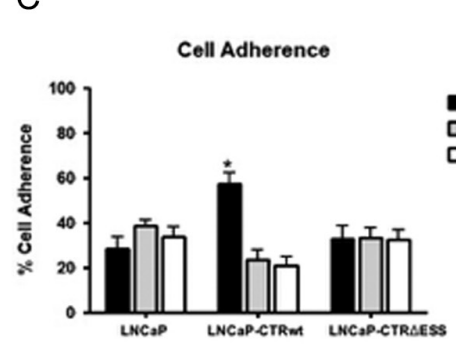

D1

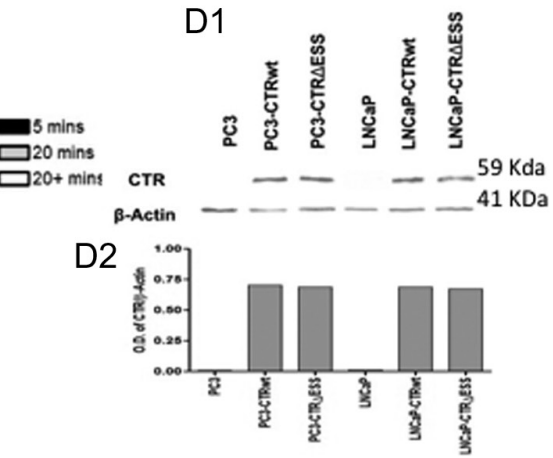

\section{Figure 1}

Fractionation of PC-3 cells. (A) Experimental protocol for fractionation of PC-3 cells on the basis of collagen adherence. (B) Percentage of PC-3 cells separated from total cells separated in each stage of fractionation. The results are expressed as mean \pm S.E.M. of percent of cells fractionated at each stage of eight separate experiments. (C) Percentage of LNCaP cells separated from total cells separated in each stage of fractionation. The results are expressed as mean \pm S.E.M. of percent of cells fractionated at each stage of eight separate experiments. $* P<0.001$ (one-way ANOVA and Newman-Keuls test (PC-3CTRwt-fast vs all other PC-3CTRwt subfractions)). (D1) CTR immunoreactivity in plasma membranes of PC-3 and LNCaP sublines expressing either CTR-wt or CTRAESS ( $50 \mu \mathrm{g}$ protein/lane) was determined by Western blot analysis. The blot was reprobed for ß-actin for normalization. Representative of three separate experiments. (D2) Optical density of CTR and actin bands on each blot was obtained by image analysis on Kodak 4000 MM Image station. The figure presents the group data (ratio of CTR OD/actin OD \pm s.E.M. of three blots).

iVision program. The program evaluated co-localization of both fluorescent dyes and calculated Pearson's co-efficient (maximum being 1.000).

For quantification of CD44 and CD133 immunostaining, the images were (positive or negative) scored by two individuals independently using established methods and the mean reading was taken (Thakkar et al. 2013). The staining intensity was assigned an arbitrary value, on a scale of $0-3$ as follows: $(-), 0$; (+/-), 0.5; (+), $1 ;(++) 2$; and (+++), 3 . An ICC index for each sample was calculated by multiplying staining intensity with the percentage of positive cells. The results were graded from 0 (negative) to 300 (all cells display strong staining intensity). Reproducibility of the analysis was verified by rescoring of randomly chosen slides. Duplicate readings gave similar results.

\section{Statistical analysis}

Statistical calculations were performed using Prism 5 computer program (GraphPad Software). Results are generally expressed as mean IHC index \pm standard error of the mean (s.E.M.) unless otherwise stated. $P<0.05$ was considered to indicate a statistically significant result. One-way ANOVA and $t$-tests were used to compare CD44/CD133 ICC index across the cell fractions.

\section{Immunohistochemistry}

Paraffin-embedded specimens were deparaffinized, hydrated, subjected to antigen retrieval by heating the slides for $5 \mathrm{~min}$ in $5 \mathrm{mM}$ sodium citrate. The sections were then stained for prostate stem cell antigen (PSCA) as previously described (14). Incubations with primary antibodies were followed by FITC-conjugated secondary antibodies. The slides were then counterstained with DAPI.

\section{Controls}

Tissue sections were incubated either in the presence of no primary antibody, or no secondary antibody.

\section{MTT assay}

The proliferation of PC cells was assessed by MTT assay using kit purchased from American Type Culture Collection. 
Exponentially growing cells were plated in a 96-well plate at a density of $8 \times 10^{3}$ cells per well and cultured for $24 \mathrm{~h}$. The complete growth medium was then replaced with $100 \mu \mathrm{L}$ of basal incubation medium (RPMI 1640 containing $0.1 \%$ BSA, $10 \mathrm{mM}$ HEPES, $4 \mathrm{mM}$-glutamine, $100 \mathrm{IU} / \mathrm{mL}$ penicillin $\mathrm{G}$, and $100 \mathrm{~g} / \mathrm{mL}$ streptomycin), and the culture was continued at $37^{\circ} \mathrm{C}$ under $5 \% \mathrm{CO}_{2}$ for $24 \mathrm{~h}$. The cells were then treated with MTT solution at $37^{\circ} \mathrm{C}$ for $4 \mathrm{~h}$, and the color reaction was stopped with the stop solution $(100 \mathrm{~L} /$ well). The incubation was continued until the formazan product was completely dissolved. Absorbance of the samples was read at $595 \mathrm{~nm}$ with an ELISA plate reader (Bio-Rad Laboratories, Inc.).

\section{Wound-healing assay}

The cells were plated in eight-chamber cell culture slides until they were $80 \%$ confluent. Wound was formed by a single scratching of $20 \mu \mathrm{L}$ pipette tip on a cell layer. The culture was continued overnight in starvation medium (basal incubation medium). Next day, the migrated cells were counted under the microscope and photographed.

\section{In vitro invasion assay}

PC cells (40,000 is optimum) were plated in serum-free media on Matrigel-coated transwell inserts (Corning, Bedford, MA, USA) with the lower chambers containing growth media with $10 \%$ FBS. After $24 \mathrm{~h}$, the cells were washed with PBS. The invaded cells (on the outside bottom of transwell insert) were stained using Diff Quick stain kit. The stained cells were counted under the microscope.

\section{Soft Agar clonogenic assays}

Soft agar assays were performed as described previously (Thomas et al. 2006). An underlay of $0.5 \%$ agar in RPMI 1640 containing 5\% fetal calf serum was prepared by mixing equal volumes of 1\% agarose and 2 RPMI 1640 plus $10 \%$ fetal calf serum. Two milliliters of this mixture were pipetted into the wells of six-well plates and allowed to set. Cells $\left(5 \times 10^{3}\right)$ were seeded in each well of a six-well culture dish containing 0.3\% top low-melt agarose. The agarose was allowed to set, and the plates were incubated in a humidified chamber at $37^{\circ} \mathrm{C}$ for 14 days. Colonies were counted in a blinded manner using a 10 objective on a Zeiss inverted microscope (Carl Zeiss). Colonies with a diameter larger than $50 \mathrm{~m}$ were scored. Data are expressed as average number of colonies formed as well as the average diameter of colonies.

\section{Spheroid formation assay}

Spheroids were prepared from single cell suspension of prostate cell lines as described before (Thomas et al. $2007 a$ ). In brief, $5 \times 10^{4}$ per mL cells in RPMI 1640 serumfree medium were placed on 96-well low-attachment tissue culture plates. The plates were rocked on gyrotory shaker in a $\mathrm{CO}_{2}$ incubator at $37^{\circ} \mathrm{C}$ for 2 days, at the end of which the spheroids measuring $150-300 \mu \mathrm{m}$ in diameter $\left(\sim 4 \times 10^{4}\right.$ cells/spheroid) were formed. Spheroids greater than $50 \mu \mathrm{m}$ were counted.

\section{Results}

\section{Fractionation of PC cell lines on the basis of collagen adherence}

Collagen adherence of PC-3 cells was remarkably increased following the expression of CTR-wt, and to a smaller extent with CTR- $\triangle$ ESS (Fig. 1B). Among different fractions, only $20 \%$ of PC3-v cells were fast adherents. This increased to almost $80 \%$ for PC3-CTRwt, but was about $50 \%$ for PC3-CTRAESS. A significant decline in non-adherent PC3 cell subpopulation was observed. This fraction consisted of almost $35 \%$ of PC3-v cells, but only 5 and $15 \%$ of cells expressing CTRwt and CTR $\Delta$ ESS respectively. LNCaP cell subfractions also exhibited very similar characteristics (Fig. 1C). To ensure that the differences in adhesion of cells expressing CTR-wt or CTR-DESS were not due to the differences in relative levels of CTR in these sublines, we analyzed CTR immunoreactivity in all PC-3 and LNCaP cell sublines by Western blot analysis. The results of Fig. 1D show that CTRwt and CTR- $\triangle$ ESS levels in respective PC-3 and LNCaP cell lines were relatively very similar, which suggests that the differences in adhesive properties of PC-3 and LNCaP sublines were entirely due to the differences in the functional properties of CTR-wt and CTR- $\Delta$ ESS.

\section{Effect of CT-CTR axis activation on the expression of stem cell antigens}

Recent studies have shown that stem cell antigens CD44, CD133 and $\alpha 2 \beta 1$ are associated with tumorigenic/ adherent properties of PC cells. It has been shown that PC-3 cells express CT, but not CTR (Chigurupati et al. 2005). Therefore, the expression of CTR will activate CT-CTR autocrine axis. We examined the influence of CTR-wt and CTR- $\triangle E S S$ on the expression of stem cell antigens CD44 and CD133. We fractionated the cells on 
the basis of their adherence to collagen 1 . As expected, $\alpha 2 \beta 1$ antigen expression of all fractions was high in both cell lines (Table 1). However, both cell lines displayed significant differences in the expression of CD44 and CD133 among these fractions.

The fast adherent fraction of PC-3 cells exhibited very low percentage of cells expressing CD44 expression (1.62\%) and CD133 $(0.8 \%)$. In contrast, the percentage of cells expressing CD44 (34.54\%) and CD133 (38.23\%) was very high in fast adherent PC3-CTRwt subfraction. Corresponding percentages of CD44- and C133-positivity for PC3-CTR $\triangle E S S$ subfraction was relatively moderate at about 14 and 17.15 respectively (Table 1; Supplementary Figs 1, $2,3,4,5,6,7,8$ and 9, see section on supplementary data given at the end of this article). Similarly, fast adherent subfractions of LNCaP cells also displayed similar characteristics (Table 1, Supplementary Figs 10, 11, 12, 13, 14, 15, 16, 17 and 18). For example, CD44-positive cell population was only $1.88 \%$, but increased to $38.12 \%$ when CTR-wt was overexpressed. The increase was very moderate $(9.12 \%)$ when CTR- $\Delta$ ESS was expressed. The corresponding increases of CD133 expression in fast adherent LNCaP subfractions were $24.87 \%$ (CTRwt) and $0.81 \%$ (CTR $\triangle \mathrm{ESS}$ ) as compared to $0.42 \%$ for the vector-control LNCaP cells (Table 1 ).
Among slow adherents, the profile of both cell lines was similar to that of fast adherents qualitatively but more moderate in extent. For example, only 3\% of low adherent PC-3 cells expressed either C44 and CD133. However, the expression of CTRwt or CTR- $\Delta$ ESS induced a subtle shift in the percentage of cell expressing these antigens. For example, CD44-positive cells increased from 3 to $12.94 \%$ when CTRwt was expressed. Corresponding increase in CD133 expression was slightly higher at $16.9 \%$. Similarly, the corresponding numbers for CTR- $\triangle \mathrm{ESS}$ cells were 14.9 and $8.9 \%$ respectively. These results again suggest that the expression of CTR induces the expression of stem cell antigens CD44 and CD133. However, the increase is remarkably smaller than that seen in fast adherents. In case of LNCaP subfractions, CD44 was expressed by $2.97 \%$ of LNCaP-vector control cells. This increased to $17.37 \%$ with CTR-wt expression, but decreased to $8.37 \%$ when CTR- $\triangle$ ESS was expressed. Similar changes were observed in CD133 as well (Table 1).

Interestingly, CTR $\Delta \mathrm{ESS}$, but not CTR-wt, caused a remarkable increase in CD44 and CD133 expression in non-adherent cell population of both cell lines.

Next, we examined whether same cells exhibit both stem cell antigens CD44 and CD133. We verified this by double ICC of collagen-fractionated PC cell lines.

Table 1 Expression of stem cell antigens

\begin{tabular}{l}
\hline Percent CD44-positive cells \\
\hline PC3v \\
PC3-CTRwt \\
PC-3-CTR ESS \\
Percent CD133-positive cells \\
PC3v \\
PC3-CTRwt \\
PC-3-CTR ESS \\
Percent $\alpha 2 \beta 1$-positive cells \\
PC3v \\
PC3-CTRwt \\
PC-3-CTR ESS \\
Percent CD44-positive cells \\
LNCaPv \\
LNCaP-CTRwt \\
LNCAP-CTR ESS \\
Percent CD133-positive cells \\
LNCaPv \\
LNCaP-CTRwt \\
LNCaP-CTR EESS \\
Percent $\alpha 2 \beta 1-$ positive cells \\
LNCaPv \\
LNCaP-CTRwt \\
LNCaP-CTR ESS
\end{tabular}

\begin{tabular}{|c|c|}
\hline Fast adherents & Slow adherents \\
\hline 1.62 & $3.18^{a}$ \\
\hline 34.54 & $12.9^{a}$ \\
\hline 14.11 & 14.94 \\
\hline 0.8 & $3.0^{\mathrm{a}}$ \\
\hline 38.23 & $16.09^{a}$ \\
\hline 17.15 & $8.90^{a}$ \\
\hline 91.49 & $94.62^{a}$ \\
\hline 97.21 & $86.18^{a}$ \\
\hline 86.87 & 87.07 \\
\hline 1.88 & $2.97 a$ \\
\hline 38.12 & $17.37 a$ \\
\hline 9.12 & 8.71 \\
\hline 0.42 & $2.77^{a}$ \\
\hline 24.87 & $18.49 a$ \\
\hline 0.81 & $4.13^{a}$ \\
\hline 95.81 & $92.13^{a}$ \\
\hline 94.03 & $92.21^{a}$ \\
\hline 83.81 & $89.13^{a}$ \\
\hline
\end{tabular}

\begin{tabular}{|c|c|}
\hline Non-adherents & Antibody controls \\
\hline $4.61^{a b}$ & $0.51 \mathrm{abc}$ \\
\hline $1.72^{\mathrm{ab}}$ & $0.88 \mathrm{abc}$ \\
\hline $24.93^{a b}$ & $1.1 \mathrm{abc}$ \\
\hline $4.82^{\mathrm{ab}}$ & $0.51 \mathrm{abc}$ \\
\hline $2.26^{a b}$ & $0.68 \mathrm{abc}$ \\
\hline $23.50^{a b}$ & $0.97 a b c$ \\
\hline $90.7 \mathrm{~b}$ & $0.35^{a b c}$ \\
\hline $28.4^{\mathrm{ab}}$ & $2.71 a b c$ \\
\hline $81.64^{a b}$ & $0.36 \mathrm{abc}$ \\
\hline 4.79ab & $0.63 a b c$ \\
\hline 5.49ab & $0.65 \mathrm{abc}$ \\
\hline $11.37 \mathrm{ab}$ & $0.37 \mathrm{abc}$ \\
\hline $5.01 \mathrm{ab}$ & $0.46 \mathrm{bc}$ \\
\hline $2.68^{a b}$ & $0.29 \mathrm{abc}$ \\
\hline $10.15^{\mathrm{ab}}$ & $0.65 b c$ \\
\hline $92.15^{a}$ & $0.25^{a b c}$ \\
\hline $57.98 \mathrm{ab}$ & $0.88 \mathrm{abc}$ \\
\hline $93.25^{a b}$ & $0.25^{a b c}$ \\
\hline
\end{tabular}

The percentile proportions depicting flow cytometry measurements over ten thousand events of all the four groups (control, fast adherents, slow adherents and non-adherents) from both the PC3 and LNCaP cell lines were individually compared with each other using Chi-squared test analysis recommended by Campbell and Richardson. The confidence interval was set at $95 \%$ and the statistical differences were denoted by acompared to control group, bcompared to fast adherent group, and ccompared to slow adherent group as significant for $P$ values less than 0.05 . 

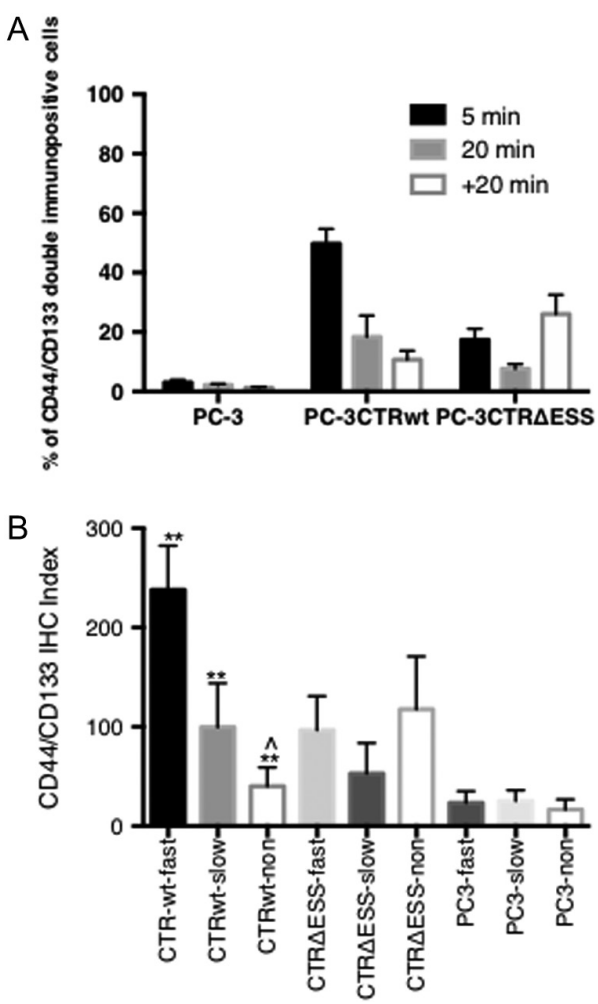

Figure 2

Co-expression of CD44/CD133 on surface of PC-3 cells. (A) Percentage of cells double-stained with CD44/CD133 antibodies. The results are mean \pm S.E.M. of four separate experiments. (B) CD44/CD133 immunocytochemistry of PC-3 cell subfractions. Fast-, slow- and non-adherent fractions of PC-3, PC-3-CTRwt and PC-CTR- $\triangle$ ESS cells were double-labeled for CD44 and CD133 as described in 'Methods' section. The slides were photographed and their $\mathrm{IHC}$ index was calculated. The results are mean \pm S.E.M. of three separate experiments. **Significantly different from its corresponding PC-3 subfraction. Level of significance: $P<0.001$ (one-way ANOVA and Newman-Keuls test). For example, PC-3-CTRwt fast vs PC-3 fast; PC-3CTRwt slow vs PC-slow; PC-3CTRwt-non vs PC-3-non. $\wedge$ Significantly different from PC-3 CTRwt fast or PC3-CTRwt-slow. Levels of significance: $P<0.01$ (one-way ANOVA and Newman-Keuls test).

Analysis of co-localization suggested that almost all cells co-localized CD44 and CD133, with Pearson's co-efficient of 0.93 . The results of Fig. 2A suggest that the percentage double-labeled cells in collagen fractions of PC cells were comparable to those in Table 1 , and raise a possibility that the expression of CTRwt enhance the adherence of PC-3 cells on collagen, also increase the expression of CD44 and CD133 in same cells. Moreover, we observed a similar increase in the IHC index suggesting the increase in the amounts of CD44/CD133 antigens per cell (Fig. 2B). CTR- $\triangle$ ESS moderately increased collagen adherence as well as CD44, CD133 expression.

Slow adherent CTRwt cells and CTR $\triangle$ ESS cells also expressed higher CD44/CD133 expression as compared to non-adherents, but this increase was remarkably lower as compared to that observed in fast adherent fractions.

\section{Effect of CTR-CTR axis activation on rate of cell proliferation}

Earlier studies from this and other laboratories reported that the activation of CTR-CTR axis led to a moderate increase in the rate of cell proliferation (Thomas et al. 2006, Shah et al. 2009a). We reexamined this phenomenon in fractionated cells on the basis of their collagen adherence. The results of Fig. 3 show that all three subfractions of PC3 cells displayed a similar rate of cell proliferation. However, the expression of CTRwt caused a significant, two-fold increase in the rate of proliferation among fast adherent cells. No significant change was observed in other two cell fractions. CTR $\Delta$ ESS caused a smaller increase in cell proliferation of fast adherent cells. These results suggest that a subpopulation of PC3 cells displaying high collagen adherence are much more responsive to CT-CTR activation than the remaining subpopulations.

\section{CT-CTR axis and tumorigenic potential, self-renewal and invasiveness}

In a wound-healing assay, we observed that the fast adherent fraction of PC-3v cells showed much greater migration than the slow adherent fraction. CT-CTR activation by the CTR- $\Delta$ ESS did not have any significant impact on overall migratory characteristics. In contrast, the activation of CT-CTR axis by CTRwt led to over a sevenfold increase in the migration of fast adherent fraction. The other two fractions also displayed remarkable increase in their migratory capacity (Fig. 3), demonstrating the importance CTR-C PDZ-binding site for this CTR action (Aljameeli et al. 2016).

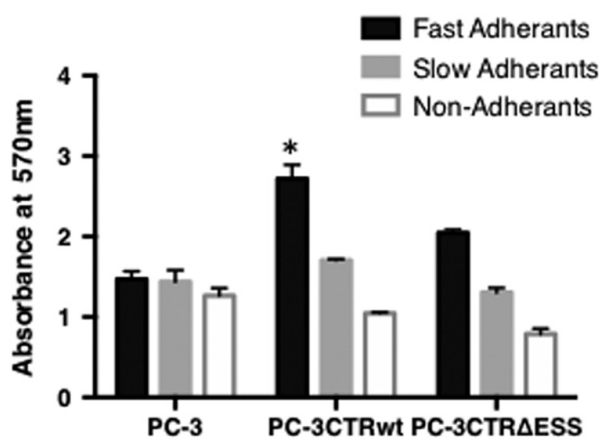

Figure 3

Rate of cell proliferation of PC-3 cell subfractions: Effect of CTR. Fastslow-and non-adherent fractions of PC-3, PC-3CTR and PC3-CTRAESS cells were analyzed for cell proliferation by MTT assay as described in 'Methods' section. The results are expressed as mean \pm S.E.M. of four separate experiments. ${ }^{*} P<0.001$ (one-Way ANOVA and Newman-Keuls test (PC-3CTRwt-fast vs all other PC-3CTRwt subfractions)). (c) 2019 Society for Endocrinology Published by Bioscientifica Ltd. Printed in Great Britain 


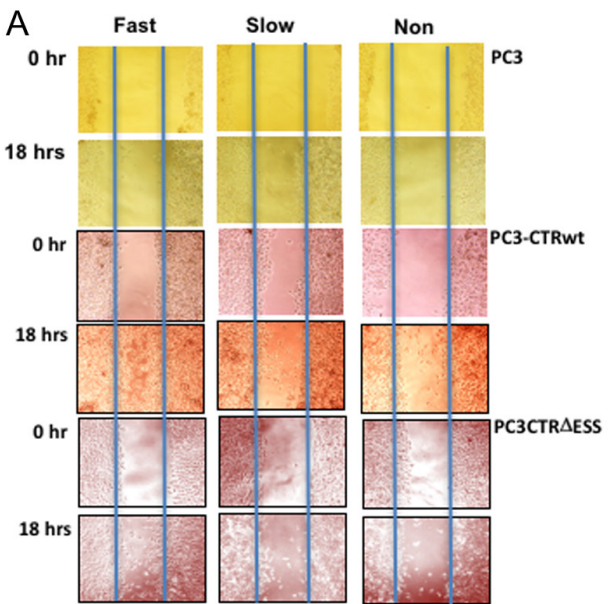

Matrigel ${ }^{\mathrm{TM}}$ invasion assays also displayed very similar results (Fig. 4). CTRwt remarkably increased invasion of all subfractions, but fast adherents were most invasive. Once again, CTR- $\Delta$ ESS did not have any stimulatory effect on invasion of all subfractions.

Stem cell-like cancer cells display the ability to form floating spheroids (known as colonospheres) in a serumfree defined medium. It has been suggested that this ability to aggregate in spheroids indicates the self-renewal capacity of stem cell-like cancer cells (Shaheen et al. 2016). We examined the capacity of PC-3 subfractions to form spheroids, and the influence of CTRwt and CTR- $\triangle \mathrm{ESS}$ in this process. Both, CTRwt and CTR $\Delta$ ESS increased spheroid formation of PC-3 cells. But CTRwt was significantly more potent than CTRAESS (Fig. 5). Once again, fast adherent fractions displayed most self-renewal capacity as assessed by spheroid formation ability.

Cancer cells, but not normal cells, can grow in the absence of substratum or anchorage-independent growth (Thomas et al. 2006). Growth in soft agar in the form of colonies is also reflective of their tumorigenicity, that is, their ability to invade and grow in unnatural environment and form metastases. We examined this property or clonogenicity of PC-3 subfractions. The ability of PC-3 cell subfractions to form colonies over agar was robustly increased only with the expression of CTRwt, but not CTRAESS (Fig. 6).

\section{Orthotopic tumor growth and formation of distant metastases in nude mice}

Next, we examined whether fast adherent cells are more tumorigenic and aggressive than slow adherents and whether CTRwt and CTR $\Delta$ ESS have an influence on their tumorigenicity and metastatic capacity. Fast adherent cells expressing CTRwt developed tumor within
15 days compared to 30 days for fast adherent PC-3 cells without CTR. Moreover, fast adherent PC-3 CTRwt cells showed significantly larger mass of prostate tumor as compared to slow adherent PC-3CTRwt cells as assessed by wet weight of the prostate at necropsy (Fig. 7A).
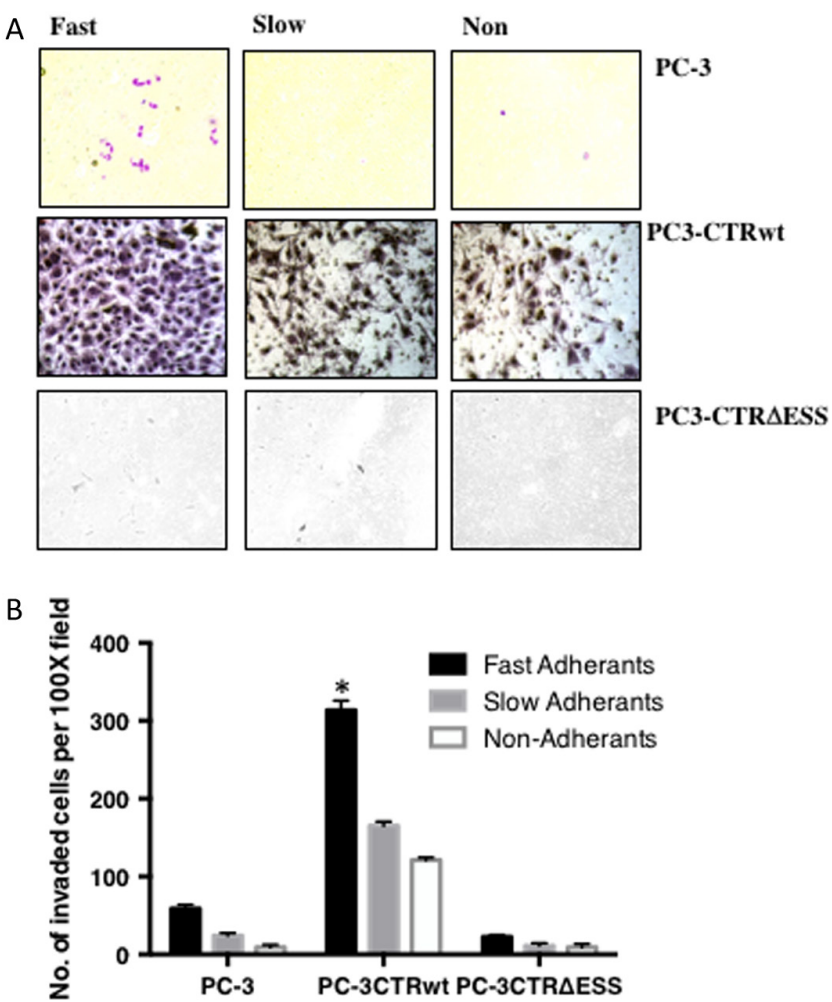

\section{Figure 5}

Invasion of PC-3 cell subfractions: Effect of CTR. Fast-, slow-and nonadherent fractions of PC-3, PC-3CTR and PC3-CTR $\triangle$ ESS cells were analyzed for cell invasion in a wound healing assay. The results are presented as (A) representative micrographs as well as (B) pooled data of four separate experiments (mean \pm S.E.M.). ${ }^{*} P<0.001$ (one-way ANOVA and NewmanKeuls test (PC-3CTRwt-fast vs all other PC-3CTRwt subfractions)). A full colour version of this figure is available at https://doi.org/10.1530/ ERC-19-0333.
2019 Society for Endocrinology Published by Bioscientifica Ltd. Printed in Great Britain 
A Fast
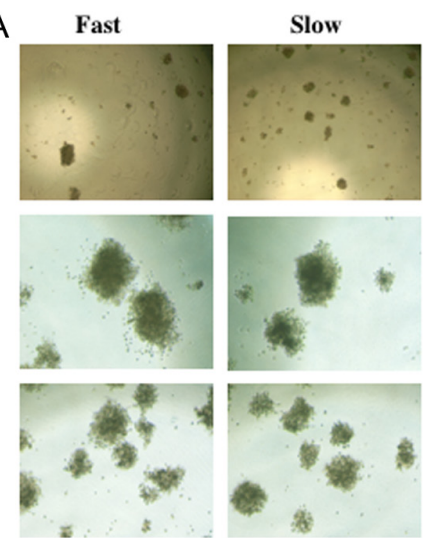$$
\text { (1) }
$$

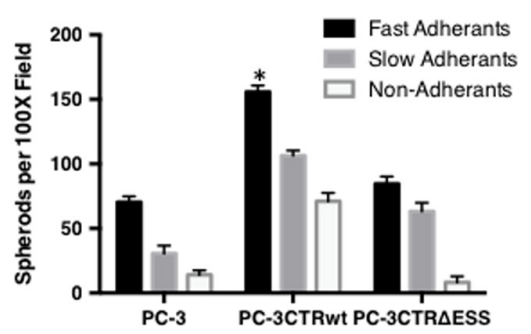

Figure 6

Spheroid formation by PC-3 cell subfractions: Effect of CTR. Fast-, slow- and non-adherent fractions of PC-3, PC-3CTR and PC3-CTR $\triangle E S S$ cells were analyzed for their ability to form spheroid in defined conditions as described in 'Methods' section. The results are presented as (A) representative micrographs as well as (B) pooled data of four separate experiments (mean \pm s.E.M.). $* P<0.001$ (one-way ANOVA and NewmanKeuls test (PC-3CTRwt-fast vs all other PC-3CTRwt subfractions)). A full colour version of this figure is available at https://doi.org/10.1530/ ERC-19-0333.

Interestingly, the fast adherent PC-3-CTRAESS cells formed even smaller tumors than the corresponding fraction of PC3-v cells, further conforming our previous report that the CTR-C PDZ-binding site is critical for tumorigenic activity of CTR (Aljameeli et al. 2016). These results are further confirmed by H\&E histology and PSCA immunofluorescence (Fig. 7B). The results demonstrate that prostates of mice implanted with PC3-CTRwt cells completely lost normal morphology as the tissue was completely taken over by tumor cells. This was evident in both, fast adherent and slow adherent, fractions of PC3-CTRwt-cells. In contrast, the prostates receiving either fractions, fast or slow adherents of PC3-CTR $\triangle \mathrm{ESS}$ cells, displayed normal morphology and occasional presence of dividing cells in a few pockets. PSCA expression was consistent with H\&E histology.

\section{Distant metastases}

The presence of micrometastases in distant organs was examined by visualization as well as by histology and
PSCA immunofluorescence. The frequency and extent of micrometastases formed by different cell fractions in distant organs are presented in Tables 2 and 3. The results demonstrate that fast adherent cells expressing CTRwt were most aggressive in forming distant metastases, and their most favored target organs were kidneys, lungs and femur (Fig. 8). Fast adherents expressing CTRAESS were much less aggressive and formed much smaller and much less frequent metastases in lungs, femur and kidneys. These results were further corroborated by $\mathrm{H} \& \mathrm{E}$ histology and PSCA staining of those organs (Fig. 9A and B). Tables 2 and 3 describe the frequency and extent of micrometastases in host organs.

\section{Discussion}

Present results have shown that fast adherent PC cell lines expressing CTRwt displayed several characteristics attributed to stem-like prostate cancer cells such as high expression of stem cell antigens CD44 and CD133,

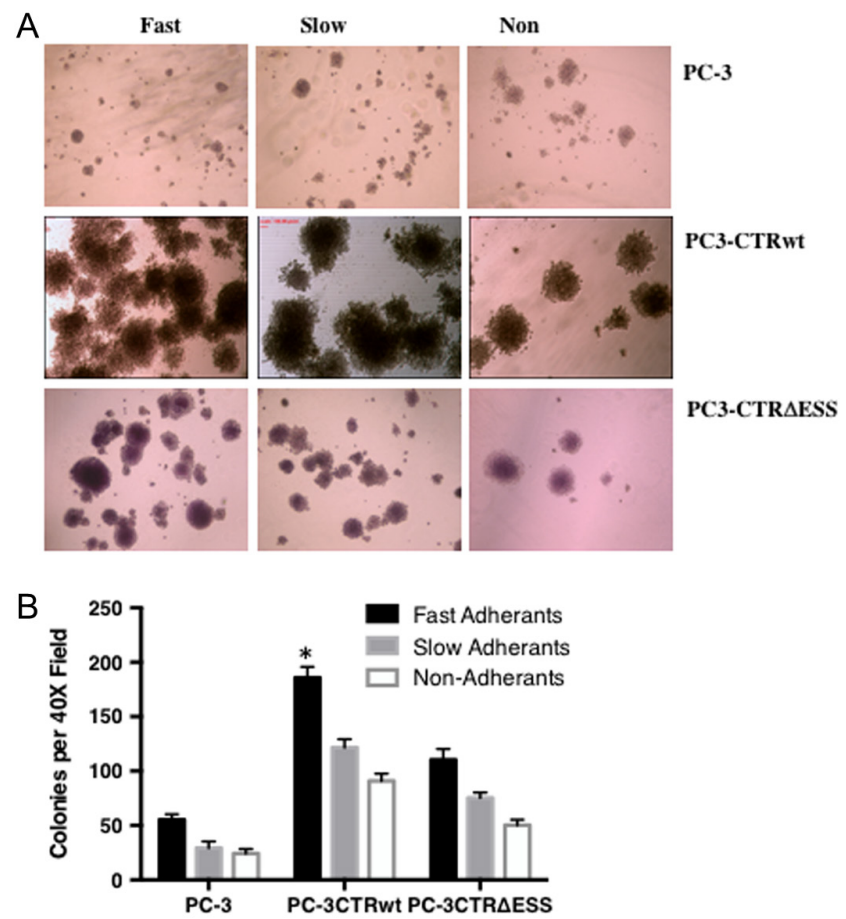

\section{Figure 7}

Clonogenicity of PC-3 cell subfractions: Effect of CTR. Fast-, slow- and non-adherent fractions of PC-3, PC-3CTR and PC3-CTRAESS cells were analyzed for clonogenic activity. The results are presented as (A) representative micrographs as well as (B) pooled data of four separate experiments (mean \pm S.E.M.). ${ }^{*} P<0.001$ (one-way ANOVA and NewmanKeuls test (PC-3CTRwt-fast vs all other PC-3CTRwt subfractions)). A full colour version of this figure is available at https://doi.org/10.1530/ ERC-19-0333.
(C) 2019 Society for Endocrinology Published by Bioscientifica Ltd. Printed in Great Britain 
Table 2 Frequency of micrometastases in host organs.

\begin{tabular}{|c|c|c|}
\hline & PC3-CTRwt & Frequency of micrometastases \\
\hline Organs & Fast adherents & Slow adherents \\
\hline Femur & 4 & 1 \\
\hline Kidneys & 6 & 2 \\
\hline Brain & 3 & 0 \\
\hline Lungs & 5 & 2 \\
\hline
\end{tabular}

\begin{tabular}{c}
\hline PC3-CTRDESS \\
\hline Fast adherents \\
\hline 1 \\
0 \\
0 \\
3 \\
\hline
\end{tabular}

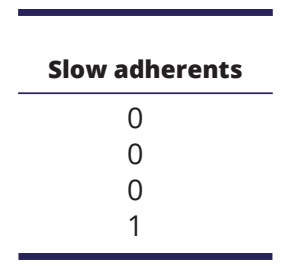

Number of animals

high proliferative, invasive, tumor-forming, metastatic and self-renewal activities. These results are consistent with our earlier results that the activation of CT-CTR axis induces an increase in tumorigenic and metastatic properties of prostate cancer cells, but further demonstrate that CT-CTR axis can also induce the expression of stem cell antigens in PC-3 cells (Sabbisetti et al. 2005, Shah et al. 2009a). Moreover, rapid adherence to collagen can be used to enrich a population of stem-like PC cells from androgen-independent PC cell lines.

Although the effect of CTR on the expression of stem cell antigens is direct or indirect remains to be investigated, present results show that CTRwt was much more potent than CTR- $\triangle$ ESS for inducing the expression CD44 and CD133 in same cells. Our recent studies have shown that CTR contains a canonical PDZ-binding site-ESSA in its cytoplasmic C-tail (Aljameeli et al. 2016). We have also shown that when CTR is activated, its PDZ-binding site binds to the PDZ3 domain of tight junction protein zonula occludens-1 (Aljameeli et al. 2016). The binding of CTR with ZO-1 facilitates the phosphorylation of ZO-1 by PKA, which consequently leads to the disassembly of tight junctions (Thakkar et al. 2016). Deletion of the PDZ-binding site with ESS-to-AAA mutation in CTR-C tail does not affect CTR-Gos interaction. The mutant receptor still activates adenylyl cyclase and subsequent signaling with equal potency as CTRwt. However, the mutation abolishes CTR-ZO-1 interaction; and as result, prevents CT-induced disassembly of tight junctions. We have shown that the binding of CTR-ZO-1 is critical for proinvasive and metastatic actions of CTR on PC cells (Aljameeli et al. 2016). Present results confirm these earlier findings, but also provide a new evidence that the mutant CTR- $\triangle \mathrm{ESS}$ was much less potent in increasing CD44/CD133 expression as well as collagen adherence of PC-3 cell subpopulations as compared to CTRwt.

CD44 is a major stem cell antigen and functions as a receptor for hyaluronan and many other extracellular matrix (ECM) components (Ghatak et al. 2010). It also serves as a cofactor for growth factors and cytokines. Thus, CD44 is a signaling platform that integrates cellular microenvironmental cues with growth factor and cytokine signals and transduces signals to the membrane-associated cytoskeletal proteins or to the nucleus to regulate a variety of gene expression levels related to cell-matrix adhesion, cell migration, proliferation, differentiation, and survival (Iczkowski et al. 2006, Iczkowski 2010). Accumulating evidence indicates that CD44, especially CD44v isoforms, are critical players in regulating the properties of stemlike cancer cells including self-renewal, tumor initiation, metastasis, and chemo/radioresistance. Significantly, CD44 has been identified as a typical stem-like cancer cell surface marker, individually or in combination with other marker(s) such as CD24, CD133, and CD34 (Shi et al. 2010, Yan et al. 2015).

Present results from this laboratory, that CTRwt induced a remarkable increase in CD44/CD133 expression in PC cells, are consistent with our earlier studies that CT induces a five-fold increase in the mRNA expression of the variant CD44v7-10, which favors fibronectin binding (Iczkowski et al. 2006). Integrins are known to play an important role in modulating the ability of tumor cells to adhere to adjacent cells and to the ECM and in PC metastasis (Thomas et al. 2007a, Desgrosellier \& Cheresh 2010). For example, when PC cells lose androgen sensitivity after androgen ablation therapy, the tumors become highly invasive and metastatic, an effect that is partly mediated via the $\alpha 6 \beta 4$ integrins and an intact p38 pathway (Bonaccorsi et al. 2000). It is likely that CD44, especially v7/v9 variant, plays a key role in adhesion/invasiveness of PC cells because the silencing of CD44v9 expression led to significant reduction in Matrigel invasion of PC-3 cells (Iczkowski et al. 2005). This possibility is further corroborated by the report that CD $44^{+}$population from xenograft tumors and cell lines has enhanced proliferative potential and tumor-initiating

Table 3 Micrometastases in host organs.

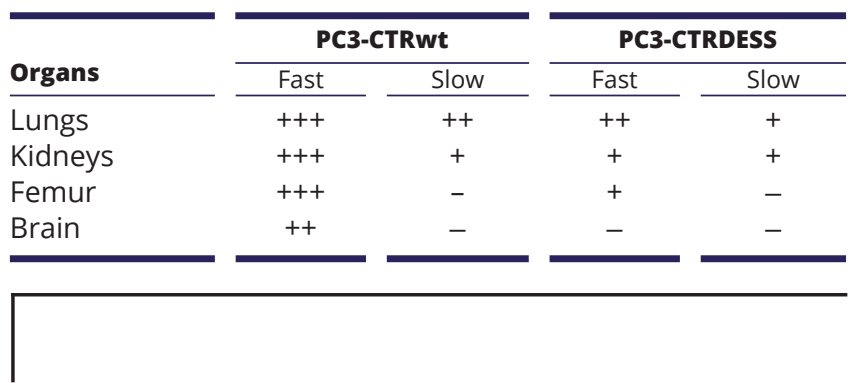



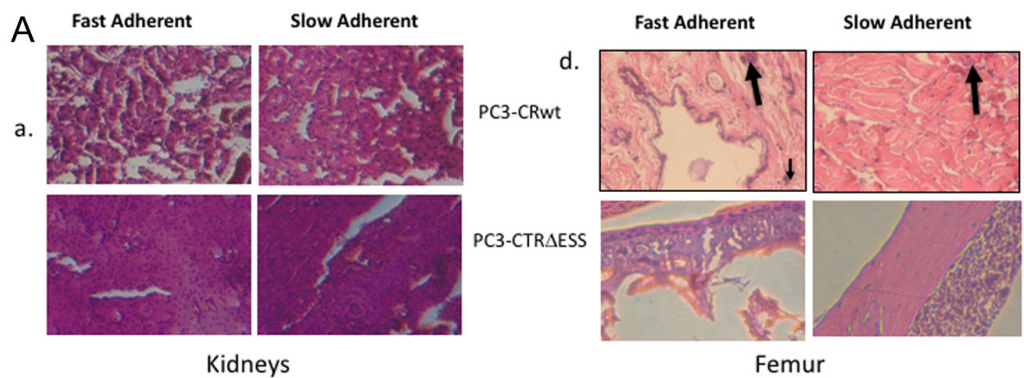

Kidneys

b.

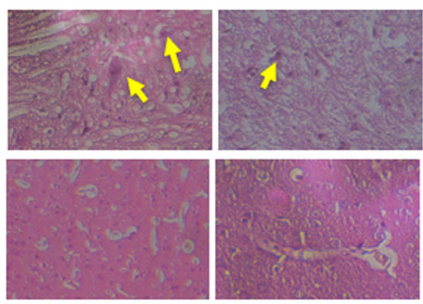

Brain
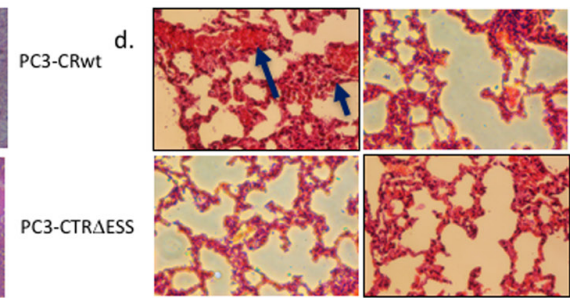

Lungs
B

PC3-CRwt Fast

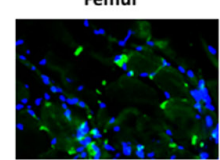

PC3-CTRwt Slow

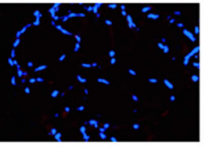

PC3-CTRAESS Fast

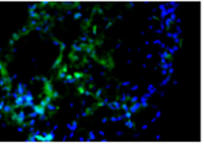

PC3-CTR $\triangle$ ESS Slow

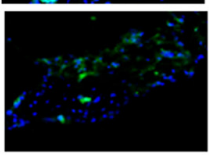

Lungs
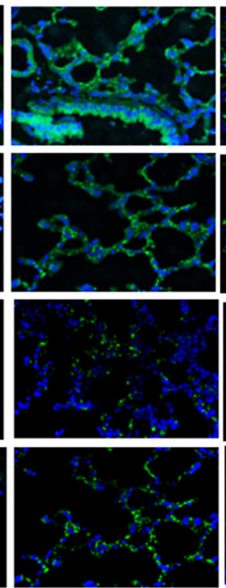

Kidneys
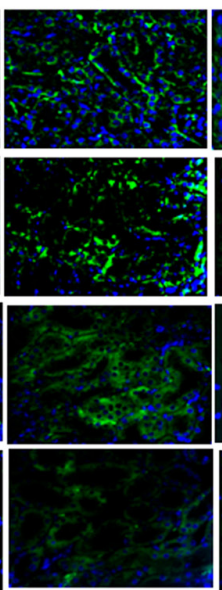

Brain
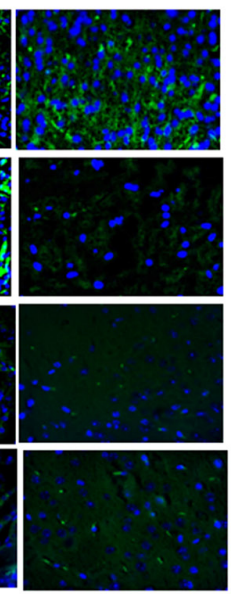

C Area Percentage of Micrometastases
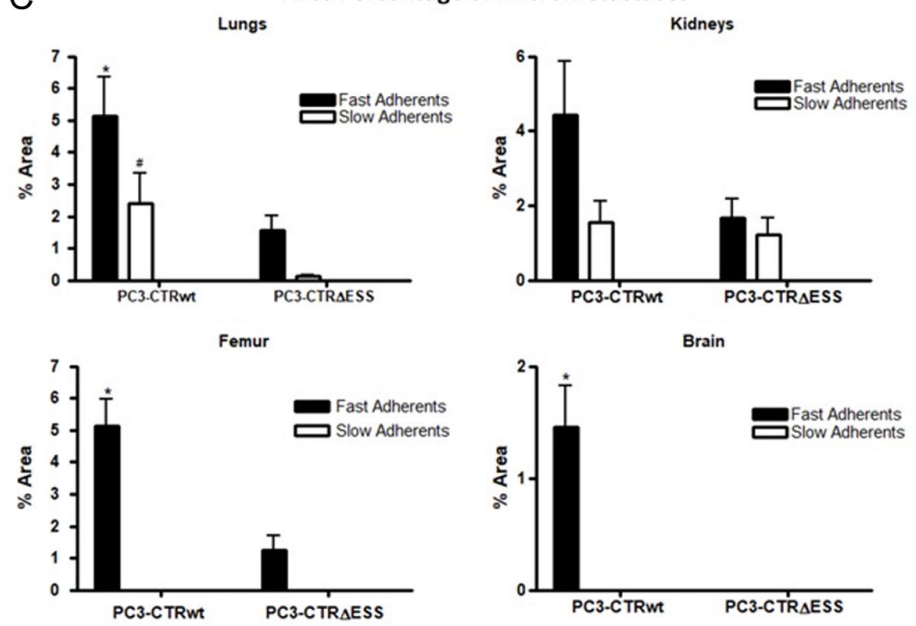

Figure 8

Distant micrometastases in nude mice. (A) Representative photomicrographs of H\&E stained tissues of nude mice (as labeled) implanted orthotopically with fast/slow adherent PC-3-CTR-wt and PC-3-CTRAESS cells (Magnification 400x). Presence of micrometastases is indicated by arrows. (B) The presence of micrometastases in distant organs presented in Fig. 9A was confirmed by PSCA immunofluorescence. (C) Mean area of micrometastases was measured over total microscopic optical field (40x) for fast/slow adherent PC-3-CTR-wt and PC-3-CTR $\triangle E S S$ cells and represented as percentile of total area. ${ }^{*} P<0.05$. Fast adherent (PC-3-CTR-wt vs PC-3CTR $\triangle E S S$ ); $\# P<0.05$ slow adherent (PC-3-CTR-wt vs PC-3-CTR $\triangle E S S)$; one-way ANOVA and Newman-Keuls test. A full colour version of this figure is available at https:// doi.org/10.1530/ERC-19-0333. 


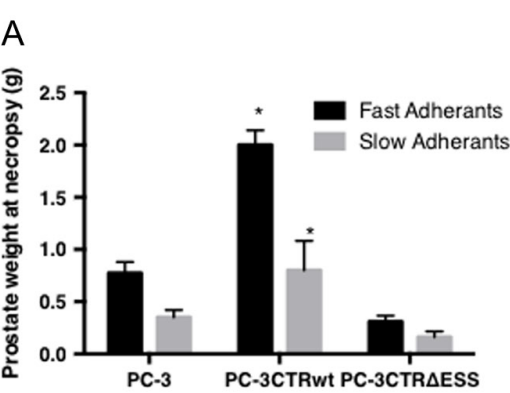

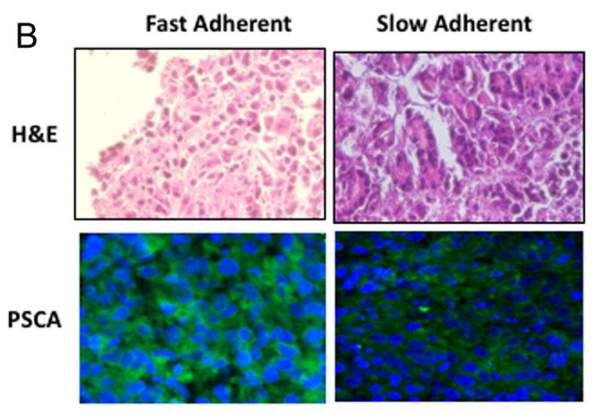

PC3-CTRwt

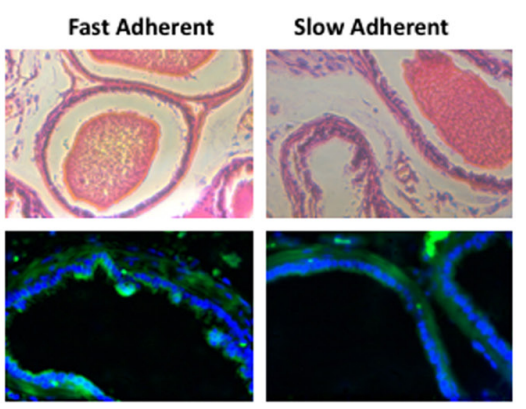

PC3-CTRAESS

\section{Figure 9}

Tumorigenicity of PC-3 cell subfractions: Effect of CTR. (A) Orthotopic tumors formed by PC-3v, PC-3CTRwt and PC-3CTRAESS cells in nude mice. PC-3 cells were transfected either with vector $(v), C T R$-wt or CTR- $\triangle$ ESS constructs. The cells $\left(1 \times 10^{6}\right)$ were orthotopically implanted into the prostate of nude mice ( $n=6$ per group). Animals were killed 8 weeks after implantation, and prostate tumors were weighed (A). *P<0.01 (PC-3v vs PC-3CTRwt); $\wedge$ < 0.01 (PC3CTRAESS vs PC-3CTRwt); one-way ANOVA and Newman-Keuls test. (B) Representative photomicrographs of H\&E stained prostate sections of nude mice implanted with fast/slow adherent PC-3-CTR-wt and PC-3-CTR $\triangle E S S$ cells (Magnification 400×). The sections were also probed for prostate stem cell antigen immunofluorescence as described in Methods section. A full colour version of this figure is available at https://doi.org/10.1530/ERC-19-0333.

ability in vivo compared to CD44- cells (Wang et al. 2013). The $\mathrm{CD}_{4} 4^{+}$cells are likewise $\mathrm{AR}^{-}$and express higher mRNA levels of stemness genes such as OCT3/4 and BMI 1 (Lang et al. 2009).

CD133+ cells have been shown to display a more transient amplifying cell population phenotype with increased metabolic activity and proliferation, and a proinflammatory phenotype with high NFkb expression (Shepherd et al. 2008). Considering that PC-3CTRwt cells induced CD44/CD133 expression and also displayed significantly greater proliferation, invasion, tumorigenic, metastatic and repopulation activity, it is likely that CT may induce or activate these mechanisms through the induction of CD44/CD133 expression in PC-3 cells. However, CT has been shown to induce multiple signaling pathways such as Gos, Goq, Wnt/ $\beta$-catenin as well as PI3/Akt/survivin pathways (Shah et al. 1994, 2009a, Thomas \& Shah 2005). It is conceivable that the multiple effects of CT on proliferation, invasion, tumorigenicity, metastatic activity, chemoresistance and repopulation of tumor may be the outcome of the activation of multiple pathways as well as the induction of CD44/CD133. Our earlier studies have shown that the mutation of CTR-C PDZ-binding site is critical for G $\alpha \mathrm{S}$-mediated invasive, tumorigenic and metastatic activity of PC cells (Aljameeli et al. 2016). Present studies also demonstrate that the $\triangle$ ESS mutation in CTR completely abolished CTR-induced invasiveness, tumorigenicity and metastastic activity of PC cells. However, PC-CTR $\triangle E S S$ cells still retained their stimulatory effects on CD44/CD133 expression, collagen adhesion, cell proliferation and spheroid formation. Based on these results, it is possible to conclude that CTR-ZO-1 interaction-dependent junctional destabilization is critical for invasive, oncogenic and metastatic activity. However, CTR-ZO-1 interaction may be only partly important for CD44/CD133 induction, cell adhesion, proliferation and spheroid formation. Based on the action of CT on CD44 mRNA expression, it is conceivable that CT-induced increase in the expression of CD44/CD133 precedes the increases in adhesion, proliferation and spheroid formation. Additional studies will be necessary to examine this phenomenon in more detail.

To summarize, present results have shown that the prevention of CTR-ZO-1 interaction by $\triangle \mathrm{ESS}$ mutation abolishes tumorigenic and metastatic actions of CTR. However, the mutation partially reduces the ability of CTR to induce CD44/CD133 expression, cell adhesion, proliferation and spheroid formation. Considering that CT plays a major role in the prevention of bone resorption as well as its direct effect on osteoclast function, present results that CT induces expression of stem cell antigens as well as other CRC characteristics of PC cells and our earlier results that CT is locally produced and significantly increases metastatic potential of PC cells by inducing EMT, raises a strong possibility that $\mathrm{CT}$ produced by metastatic PC cells may help cancer cells to colonize the bone tissue by increasing their cell adhesion and through induction of stem cell antigens.

\section{Supplementary data}

This is linked to the online version of the paper at https://doi.org/10.1530/ ERC-19-0333.

\section{Declaration of interest}

The authors declare that there is no conflict of interest that could be perceived as prejudicing the impartiality of the research reported.
(C) 2019 Society for Endocrinology Published by Bioscientifica Ltd. Printed in Great Britain 


\section{Funding}

This work was supported by National Institutes of Health Grant R01CA-096534 to G V S.

\section{Acknowledgements}

Authors thank King Khaled University, Saudi Arabia for providing support to Ms Afaf Aldahish for pre-doctoral study.

\section{References}

Aljameeli A, Thakkar A, Thomas S, Lakshmikanthan V, Iczkowski KA \& Shah GV 2016 Calcitonin receptor-zonula occludens-1 interaction is critical for calcitonin-stimulated prostate cancer metastasis. PLOS ONE 11 e0150090. (https://doi.org/10.1371/journal.pone.0150090)

Beltran H, Prandi D, Mosquera JM, Benelli M, Puca L, Cyrta J, Marotz C, Giannopoulou E, Chakravarthi BV, Varambally Sv, et al. 2016 Divergent clonal evolution of castration-resistant neuroendocrine prostate cancer. Nature Medicine 22 298-305. (https://doi. org/10.1038/nm.4045)

Bonaccorsi L, Carloni V, Muratori M, Salvadori A, Giannini A, Carini M, Serio M, Forti G \& Baldi E 2000 Androgen receptor expression in prostate carcinoma cells suppresses alpha6beta4 integrin-mediated invasive phenotype. Endocrinology 141 3172-3182. (https://doi. org/10.1210/endo.141.9.7640)

Charan J \& Kantharia ND 2013 How to calculate sample size in animal studies? Journal of Pharmacology \& Pharmacotherapeutics 4 303-306. (https://doi.org/10.4103/0976-500X.119726)

Chien J \& Shah GV 2001 Role of stimulatory guanine nucleotide binding protein (GSalpha) in proliferation of PC-3M prostate cancer cells. International Journal of Cancer 91 46-54. (https://doi. org/10.1002/1097-0215(20010101)91:1<46::aid-ijc1008>3.0.co;2-0)

Chien J, Wong E, Nikes E, Noble MJ, Pantazis CG \& Shah GV 1999 Constitutive activation of stimulatory guanine nucleotide binding protein (G(S)alphaQL)-mediated signaling increases invasiveness and tumorigenicity of PC-3M prostate cancer cells. Oncogene $183376-$ 3382. (https://doi.org/10.1038/sj.onc.1202690)

Chigurupati S, Kulkarni T, Thomas S \& Shah G 2005 Calcitonin stimulates multiple stages of angiogenesis by directly acting on endothelial cells. Cancer Research 65 8519-8529. (https://doi. org/10.1158/0008-5472.CAN-05-0848)

Dell RB, Holleran S \& Ramakrishnan R 2002 Sample size determination. ILAR Journal 43 207-213. (https://doi.org/10.1093/ilar.43.4.207)

Desgrosellier JS \& Cheresh DA 2010 Integrins in cancer: biological implications and therapeutic opportunities. Nature Reviews. Cancer 10 9-22. (https://doi.org/10.1038/nrc2748)

Ferlay J, Parkin DM \& Steliarova-Foucher E 2010 Estimates of cancer incidence and mortality in Europe in 2008. European Journal of Cancer 46 765-781. (https://doi.org/10.1016/j.ejca.2009.12.014)

Ghatak S, Hascall VC, Markwald RR \& Misra S 2010 Stromal hyaluronan interaction with epithelial CD44 variants promotes prostate cancer invasiveness by augmenting expression and function of hepatocyte growth factor and androgen receptor. Journal of Biological Chemistry 285 19821-19832. (https://doi.org/10.1074/jbc.M110.104273)

Iczkowski KA 2010 Cell adhesion molecule CD44: its functional roles in prostate cancer. American Journal of Translational Research 3 1-7.

Iczkowski KA, Omara-Opyene AL, Kulkarni TR, Pansara M \& Shah GV 2005 Paracrine calcitonin in prostate cancer is linked to CD44 variant expression and invasion. Anticancer Research 25 2075-2083.

Iczkowski KA, Omara-Opyene AL \& Shah GV 2006 The predominant CD44 splice variant in prostate cancer binds fibronectin, and calcitonin stimulates its expression. Anticancer Research $262863-$ 2872.

Lang SH, Frame FM \& Collins AT 2009 Prostate cancer stem cells. Journal of Pathology 217 299-306. (https://doi.org/10.1002/path.2478)

Oktem G, Bilir A, Uslu R, Inan SV, Demiray SB, Atmaca H, Ayla S, Sercan O \& Uysal A 2014a Expression profiling of stem cell signaling alters with spheroid formation in CD133(high)/CD44(high) prostate cancer stem cells. Oncology Letters 7 2103-2109. (https://doi. org/10.3892/ol.2014.1992)

Oktem G, Sercan O, Guven U, Uslu R, Uysal A, Goksel G, Ayla S \& Bilir A 2014b Cancer stem cell differentiation: TGFbeta1 and versican may trigger molecules for the organization of tumor spheroids. Oncology Reports 32 641-649. (https://doi.org/10.3892/ or.2014.3252)

Reya T, Morrison SJ, Clarke MF \& Weissman IL 2001 Stem cells, cancer, and cancer stem cells. Nature 414 105-111. (https://doi. org/10.1038/35102167)

Sabbisetti VS, Chirugupati S, Thomas S, Vaidya KS, Reardon D, ChirivaInternati M, Iczkowski KA \& Shah GV 2005 Calcitonin increases invasiveness of prostate cancer cells: role for cyclic AMP-dependent protein kinase A in calcitonin action. International Journal of Cancer 117 551-560. (https://doi.org/10.1002/ijc.21158)

Sariisik E, Docheva D, Padula D, Popov C, Opfer J, Schieker M, ClausenSchaumann H \& Benoit M 2013 Probing the interaction forces of prostate cancer cells with collagen I and bone marrow derived stem cells on the single cell level. PLOS ONE 8 e57706. (https://doi. org/10.1371/journal.pone.0057706)

Shah GV, Noble MJ, Austenfeld M, Weigel J, Deftos LJ \& Mebust WK 1992 Presence of calcitonin-like immunoreactivity (iCT) in human prostate gland: evidence for iCT secretion by cultured prostate cells. Prostate 21 87-97. (https://doi.org/10.1002/pros.2990210202)

Shah GV, Rayford W, Noble MJ, Austenfeld M, Weigel J, Vamos S \& Mebust WK 1994 Calcitonin stimulates growth of human prostate cancer cells through receptor-mediated increase in cyclic adenosine 3',5'-monophosphates and cytoplasmic Ca2+ transients. Endocrinology 134 596-602. (https://doi.org/10.1210/endo.134.2.8299557)

Shah GV, Thomas S, Muralidharan A, Liu Y, Hermonat PL, Williams J \& Chaudhary J 2008 Calcitonin promotes in vivo metastasis of prostate cancer cells by altering cell signaling, adhesion, and inflammatory pathways. Endocrine-Related Cancer 15 953-964. (https://doi. org/10.1677/ERC-08-0136)

Shah GV, Muralidharan A, Gokulgandhi M, Soan K \& Thomas S 2009a Cadherin switching and activation of beta-catenin signaling underlie proinvasive actions of calcitonin-calcitonin receptor axis in prostate cancer. Journal of Biological Chemistry 284 1018-1030. (https://doi. org/10.1074/jbc.M807823200)

Shah GV, Muralidharan A, Thomas S, Gokulgandhi M, Mudit M, Khanfar M \& El Sayed K $2009 b$ Identification of a small molecule class to enhance cell-cell adhesion and attenuate prostate tumor growth and metastasis. Molecular Cancer Therapeutics 8 509-520. (https://doi.org/10.1158/1535-7163.MCT-08-0693)

Shaheen S, Ahmed M, Lorenzi F \& Nateri AS 2016 Spheroid-formation (colonosphere) assay for in vitro assessment and expansion of stem cells in colon cancer. Stem Cell Reviews and Reports 12 492-499. (https://doi.org/10.1007/s12015-016-9664-6)

Shepherd CJ, Rizzo S, Ledaki I, Davies M, Brewer D, Attard G, de Bono J \& Hudson DL 2008 Expression profiling of CD133+ and CD133epithelial cells from human prostate. Prostate 68 1007-1024. (https:// doi.org/10.1002/pros.20765)

Shi C, Tian R, Wang M, Wang X, Jiang J, Zhang Z, Li X, He Z, Gong W \& Qin R 2010 CD44+ CD133+ population exhibits cancer stem celllike characteristics in human gallbladder carcinoma. Cancer Biology \& Therapy 10 1182-1190. (https://doi.org/10.4161/cbt.10.11.13664)

Shibata Y, Suzuki K, Arai S, Miyoshi Y, Umemoto S, Masumori N, Kamiya N, Ichikawa T, Kitagawa Y, Mizokami A, et al. 2013 Impact of pre-treatment prostate tissue androgen content on the 
prediction of castration-resistant prostate cancer development in patients treated with primary androgen deprivation therapy. Andrology 1 505-511. (https://doi.org/10.1111/j.2047-2927. 2013.00068.x)

Thakkar A, Bijnsdorp IV, Geldof AA \& Shah GV 2013 Profiling of the calcitonin-calcitonin receptor axis in primary prostate cancer: clinical implications and molecular correlates. Oncology Reports 30 1265-1274. (https://doi.org/10.3892/or.2013.2583)

Thakkar A, Aljameeli A, Thomas S \& Shah GV 2016 A-kinase anchoring protein 2 is required for calcitonin-mediated invasion of cancer cells. Endocrine-Related Cancer 23 1-14. (https://doi.org/10.1530/ERC-150425)

Thomas S \& Shah G 2005 Calcitonin induces apoptosis resistance in prostate cancer cell lines against cytotoxic drugs via the Akt/survivin pathway. Cancer Biology \& Therapy 4 1226-1233. (https://doi. org/10.4161/cbt.4.11.2093)

Thomas S, Chigurupati S, Anbalagan M \& Shah G 2006 Calcitonin increases tumorigenicity of prostate cancer cells: evidence for the role of protein kinase A and urokinase-type plasminogen receptor.
Molecular Endocrinology 20 1894-1911. (https://doi.org/10.1210/ me.2005-0284)

Thomas S, Chiriva-Internati M \& Shah GV $2007 a$ Calcitonin receptorstimulated migration of prostate cancer cells is mediated by urokinase receptor-integrin signaling. Clinical \& Experimental Metastasis 24 363-377. (https://doi.org/10.1007/s10585-007-9073-y)

Thomas S, Muralidharan A \& Shah GV 2007b Knock-down of calcitonin receptor expression induces apoptosis and growth arrest of prostate cancer cells. International Journal of Oncology 31 1425-1437. (https:// doi.org/10.3892/ijo.31.6.1425)

Wang L, Huang X, Zheng X, Wang X, Li S, Zhang L, Yang Z \& Xia Z 2013 Enrichment of prostate cancer stem-like cells from human prostate cancer cell lines by culture in serum-free medium and chemoradiotherapy. International Journal of Biological Sciences 9472 479. (https://doi.org/10.7150/ijbs.5855)

Yan Y, Zuo X \& Wei D 2015 Concise review: emerging role of CD44 in cancer stem cells: a promising biomarker and therapeutic target. Stem Cells Translational Medicine 4 1033-1043. (https://doi. org/10.5966/sctm.2015-0048)

Received in final form 18 September 2019 Accepted 23 September 2019

Accepted Preprint published online 27 September 2019 (c) 2019 Society for Endocrinology Published by Bioscientifica Ltd. Printed in Great Britain 